\title{
Influence of progesterone and oestradiol-17 $\beta$ on blastocysts of the tammar wallaby (Macropus eugenii) during seasonal diapause
}

\author{
T. P. Fletcher, A. E. Jetton $\uparrow$ and M. B. Renfree \\ Department of Anatomy, Monash University, Melbourne, Victoria 3168, Australia
}

\begin{abstract}
Summary. Forty tammar wallabies, presumed to be carrying quiescent blastocysts, were injected with progesterone and oestradiol alone, or in combination, during seasonal quiescence when the corpus luteum is inactive. Plasma progesterone concentrations were increased to values equivalent to those of late pregnancy for the duration of the treatment in progesterone-treated groups but otherwise remained at values equivalent to seasonal quiescence. Tammars treated with low doses of oestradiol showed no measurable increase in plasma oestradiol concentrations but in those treated with high doses plasma concentrations were increased to oestrous levels. At autopsy on Day 18 after the start of treatment the embryos and reproductive tracts were assessed. While progesterone alone caused reactivation of about $50 \%$ of the embryos, blastocysts in tammars treated with oestradiol alone remained in diapause (low dose) or disappeared from the uterus (high dose): 2 blastocysts collapsed after some slight expansion. No synergistic effect on pregnancy was noted in tammars receiving both oestradiol and progesterone. We conclude that oestrogen alone is not capable of stimulating normal growth of blastocysts, and its role during early pregnancy in tammars remains unclear.
\end{abstract}

Keyw'ords: progesterone; oestradiol-17ß; blastocyst; seasonal diapause; marsupial

\section{Introduction}

During seasonal diapause (May-December) lactating female tammar wallabies (Macropus eugenii) carry a diapausing blastocyst which remains quiescent even after the sucking pouch young is removed (Tyndale-Biscoe \& Renfree, 1987). A transient rise in circulating oestradiol-17 $\beta$ at Day 5 of pregnancy has been described (Shaw \& Renfree, 1984), coinciding with an early rise in progesterone (Hinds \& Tyndale-Biscoe, 1982; Shaw \& Renfree, 1984) which has been implicated in the reactivation of the diapausing blastocyst and maintenance of early pregnancy.

Diapausing embryos can be reactivated by progesterone injections, but $10 \mathrm{mg} /$ day is needed for 10 days, and there is a $50 \%$ embryonic loss, mostly at early stages of development (Renfree \& Tyndale-Biscoe, 1973). Lower doses (1, 2 or $4 \mathrm{mg} /$ progesterone/day) for 3 days can cause reactivation of tammar blastocysts but about $75 \%$ show degenerative changes by Days 8,10 or 12 when autopsied (Berger \& Sharman, 1969). Results obtained in intact and ovariectomized females were similar, and since all uteri became secretory this suggested a direct effect on the uterus and possibly also the blastocyst. Low doses of progesterone ( 2 or $5 \mathrm{mg} /$ day) for more sustained periods (18 days) did not improve the success rate, and again most blastocysts had collapsed after they reached Day 10-12 of development (Renfree et al., 1982). These results suggest that progesterone may not act alone to induce and maintain embryonic growth.

†Present address: Department of Neurobiology \& Physiology, Northwestern University, Evanston, Illinois 60201, U.S.A. 
There is some evidence for a role of oestrogen in reactivation, and after treatment initiation of development (as measured by expansion) can occur but there is subsequent failure of the pregnancy as assessed by the presence of a collapsed or degenerating blastocyst. In about half the tammars treated during seasonal quiescence with 50 or $100 \mu \mathrm{g}$ oestradiol benzoate/day for 3 days nothing was found in the uterus at autopsy, and all blastocysts recovered had collapsed (Smith \& Sharman, 1969). Quokkas and tammars given more physiological doses of oestrogens $10 \mu \mathrm{g} / \mathrm{day}$ or $1 \mu \mathrm{g} / \mathrm{day}$ showed some expansion of blastocysts but again many were collapsed or were not found (TyndaleBiscoe, 1963; Renfree et al., 1982).

The most compelling evidence for the importance of oestrogen in early pregnancy is that treatment of lactating red kangaroos on Days 1-3 with progesterone (5-20 mg/day) or oestradiol $(20,60,100$ or $200 \mu \mathrm{g} /$ day $)$ followed by removal of pouch young on Day 4 resulted in birth occurring 3-4 days earlier than in control animals (Clark, 1968). This demonstrated that both steroids successfully initiated reactivation of the blastocysts, which were then sustained by the natural sequence of events which result from removal of the sucking stimulus. It therefore seems possible that oestrogen, alone or acting in concert with progesterone, may stimulate reactivation of blastocysts after diapause.

Most of the studies described above preceded the validation of sensitive radioimmunoassays for hormones in marsupials, and so the peripheral plasma concentrations achieved by the various steroid treatments are unknown. Further, little distinction has generally been made between initiation of development, and maintenance of pregnancy, after treatment. This study was designed to test whether acting synergistically with progesterone, or alone, oestrogen could reactivate diapausing blastocysts, and induce or sustain normal development in a high proportion of animals during seasonal quiescence. The doses were chosen to give plasma concentrations close to the endogenous levels measured during the oestrous cycle and pregnancy (Hinds \& Tyndale-Biscoe, 1982; Shaw \& Renfree, 1984; Harder et al., 1984), and radioimmunoassays of plasma samples were conducted to confirm this.

\section{Materials and Methods}

Steroid treatment. Forty tammars were allocated to 7 treatment groups. The experiment was run in 2 trials during the seasonal quiescent periods in 1984 (Groups 1-4) and 1986 (Groups 5-7). Group 1 was given $10 \mathrm{mg}$ progesterone per day for 18 days, Group 2 was given $10 \mathrm{mg}$ progesterone $+1 \mu \mathrm{g}$ oestradiol for 3 days then $10 \mathrm{mg}$ progesterone for 15 days, Group 3 was given $10 \mathrm{mg}$ progesterone $+1 \mu \mathrm{g}$ oestradiol for 10 days; Groups 4 and 5 were given $1 \mu \mathrm{g}$ oestradiol for 10 days; Group 6 was given $10 \mu \mathrm{g}$ oestradiol for 10 days; and Group 7 was given arachis oil for 10 days. All steroids were delivered in arachis oil.

Injections were given between 09:00 and 10:00 h daily for the period indicated. The day of first injection was designated Day 0 . Blood samples $(5 \mathrm{ml})$ were taken before any injection on Days $0,4,9,14$ and 18; the plasma was separated by centrifugation and stored at $-20^{\circ} \mathrm{C}$ for later assay. After the blood sample on Day 18 the animals were killed by injection of pentobarbitone sodium (Abbott Laboratories, Kurnell, NSW, Australia) and the reproductive tracts were removed. The ovary carrying the corpus luteum $(C L)$ was identified. In animals with small uteri, both sides were flushed with saline to recover the blastocysts and then opened. Animals with enlarged uteri containing advanced fetuses were carefully cut open. Any embryonic material recovered was examined under a dissecting microscope and measured with an eyepiece micrometer or vernier caliper. The endometrium and myometrium were separated as previously described (Renfree \& Tyndale-Biscoe, 1973) and weighed. In 1986, the vaginal complex in Groups 5-7 was also removed and weighed as described by Short et al. (1985).

Hormone assays. Progesterone was measured by the method of Fletcher \& Renfree (1988), validated for tammar plasma, using antiserum S334 provided by Dr R. I. Cox (CSIRO Division of Animal Production, Prospect, NSW, Australia). Efficiency of the extraction procedure was $75 \%$ and sensitivity of the assay, defined as the lowest standard which differs from the zero standard by more than twice the standard deviation of the zero standard, was $20 \mathrm{pg} / \mathrm{ml}$ for 4 assays. The inter- and intra-assay coefficients of variation were $5.0 \%$ and $14.8 \%$ for 2 plasma pools in 4 assays and $12.4 \%$, respectively. All samples from each animal were measured in the same assay.

Oestradiol was measured by the method of Shaw \& Renfree (1984), validated for tammar plasma, using antiserum S6181 provided by Dr R. I. Cox (CSIRO Division of Animal Production, Prospect, NSW). Efficiency of the extraction procedure was $92 \%$. Sensitivity of the assay was $4 \mathrm{pg} / \mathrm{ml}$. The inter- and intra-assay coefficients of variation were $5.2 \%$ and $19.1 \%$ for 2 plasma pools in 4 assays, and $5.33 \%$ respectively. All samples from each animal were measured in the same assay. 
Statistical analysis. Endometrium and myometrium weights of the gravid uteri or those ipsilateral to the CL and non-gravid uteri or those contralateral to the CL were tested for unilateral effects of pregnancy by paired Student's $t$ tests using the Minitab statistical program (Ryan et al., 1985). The effect of treatment on endometrium and myometrium weight was tested by one way analysis of variance, and Duncan's multiple range test on $\log _{10}$ transformed data using the SPSS-X information analysis system (Nie et al., 1986).

\section{Results}

\section{Plasma progesterone and oestradiol concentrations}

Elevated concentrations of progesterone in the range $1.0-2.0 \mathrm{ng} / \mathrm{ml}$ were achieved 4 days after progesterone treatment began in Groups 1,2 and 3 and were maintained for the duration of the treatment in Groups 1 and 2 (Fig. 1). In Group 3, plasma progesterone concentration had fallen to pretreatment values by 5 days from cessation of the injections on Day 10. In Groups 4-7 (control and oestradiol only treatments) progesterone concentrations remained at basal levels.

Plasma oestradiol concentrations were at normal pregnancy values and were unaffected by treatment in Group 7 (control), Group 1 (progesterone only) and Groups 2, 3, 4 and 5 (1 1 g oestradiol) (Fig. 1). Injection of $10 \mu \mathrm{g}$ oestradiol/day (Group 6) caused a marked rise of plasma oestradiol which declined slowly after cessation of treatment.

\section{Response of the maternal reproductive system}

Endometrium and myometrium. Endometrium and myometrium weights in all steroid treatment groups except those of Group 4 animals were significantly heavier than controls (Fig. 2). Endometrium and myometrium weights were tested by Student's $t$ test for unilateral effects within each treatment. There was no unilateral effect of treatment on endometrium and myometrium weight in Groups $2-7$ but in Group 1 values were significantly greater $(0.01<P<0.05)$ on the side ipsilateral to the corpus luteum.

Because there was a significant difference between the endometrium and myometrium weights from the two uteri of animals in Group 1, the data for each side and tissue were tested independently for effects of treatment by one way analysis of variance. There was a significant effect of treatment on the side ipsilateral to the corpus luteum endometrium $(0.01<P<0.05)$ and myometrium $(0.01<P<0.05)$, and endometrium $(P<0.01)$ and myometrium $(0.01<P<0.05)$ of the side contralateral to the CL.

The endometrium and myometrium weights contralateral to the CL in Group 2 were significantly greater $(P<0.05)$ than in controls (Group 7) and all other treatments (Groups 1, 3-6). Endometrium and myometrium weights ipsilateral to the CL in Groups 2 and 3 were significantly greater $(P<0.05)$ than those in controls (Group 7) and in all other treatment groups (Groups 1, 4-6) but did not significantly differ from each other $(P>0.05)$. Endometrium and myometrium weights for all other treatments were significantly greater $(P<0.05)$ than in controls and Group 4 tammars, except for myometrium weight contralateral to the $\mathrm{CL}$ in Group 4 which was also significantly greater $(P<0.05)$ than in the controls.

Lateral vaginae. The mean ( \pm s.d.) weights of the vaginal complex of the 1986 oestradiol-treated animals (Group 5: 7.1 $\mathrm{g} \pm 0 \cdot 9, \overline{\mathrm{N}}=6$; Group 6: $6.4 \mathrm{~g} \pm 1 \cdot 8, \mathrm{~N}=6$ ) was significantly greater than in the controls (Group 7): $2.9 \mathrm{~g} \pm 1.4(P<0.001$ and $P<0.001)$, (Fig. 3). The effect of oestradiol treatment was not dose-dependent $(P>0.05)$.

\section{Assessment of embryonic reactivation after treatment}

Developmental stage of embryonic material was assessed using the embryonic growth curves of Renfree \& Tyndale-Biscoe (1973) and Tyndale-Biscoe \& Renfree (1987). Injection of progesterone alone (Group 1) or in combination with oestradiol (Groups 2,3) resulted in reactivation of $6 / 6$ or 


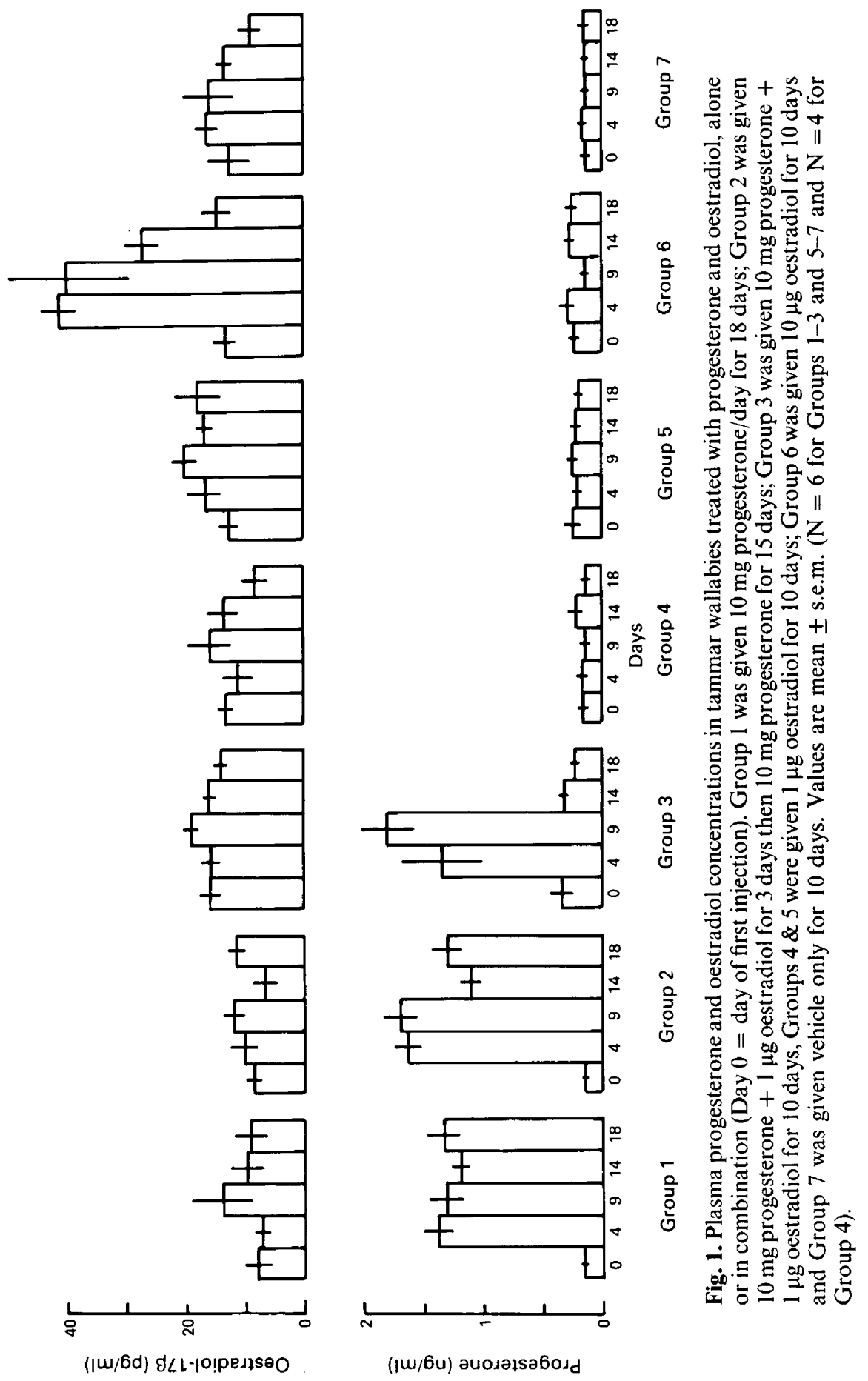




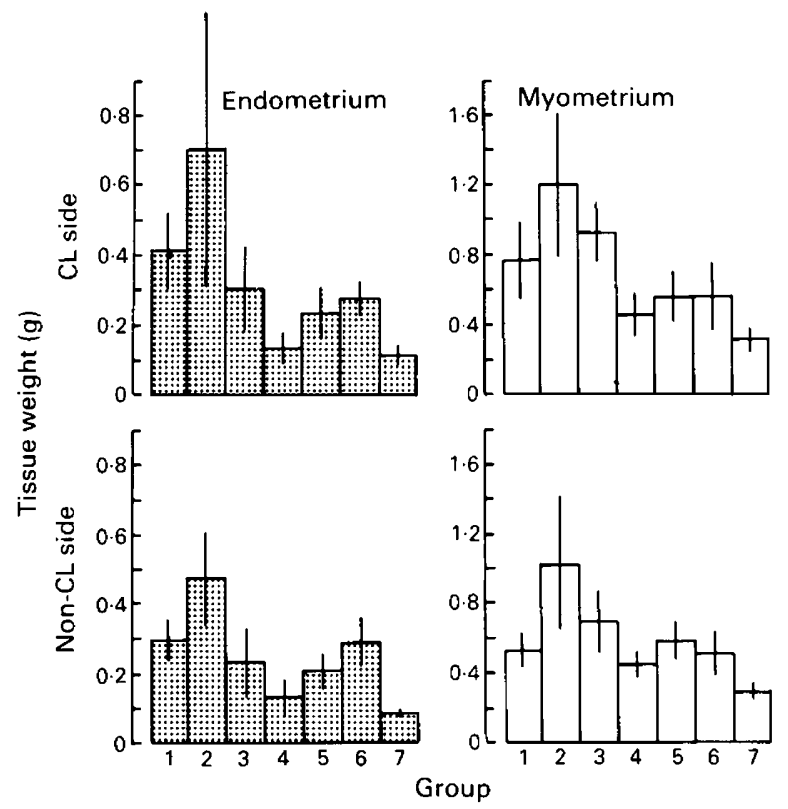

Fig. 2. Endometrium and myometrium weights on the sides ipsilateral and contralateral to the $\mathrm{CL}$ of tammars treated with progesterone and oestradiol alone or in combination. Treatments and number of animals are as in Fig. 1. Values are mean \pm s.d.

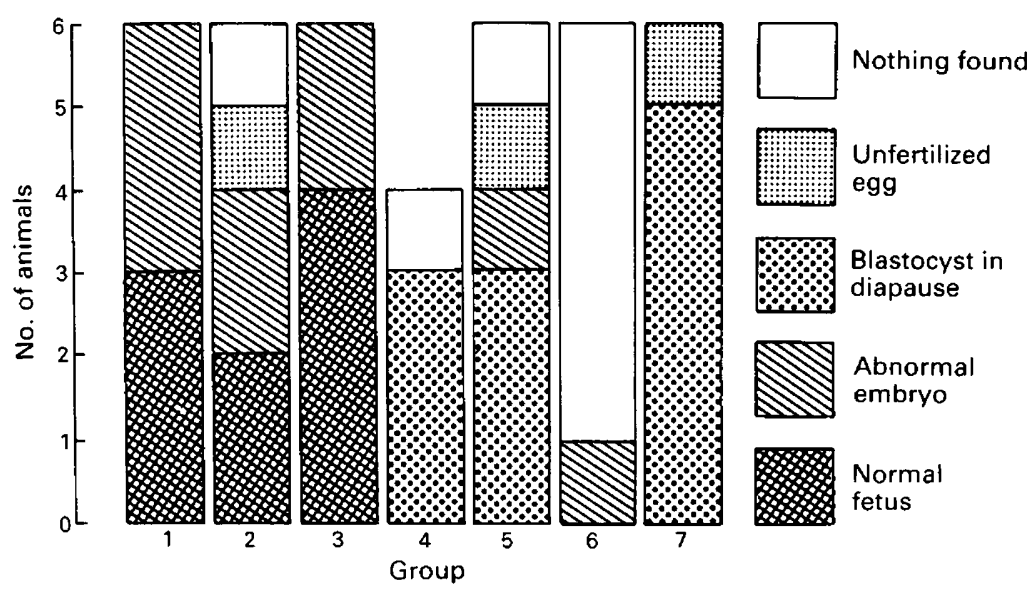

Fig. 3. The effect of treatment with progesterone and oestradiol- $17 \beta$ alone or in combination on quiescent blastocysts of the tammar during seasonal diapause. The bars indicate the numbers and condition of the blastocysts recovered at autopsy for each treatment. Treatments and numbers of animals are as in Fig. 1. 
4/6 blastocysts (Fig. 3). Although all Group 1 embryos reactivated, only 3 were normal Day 23-24 size fetuses, and the remainder were collapsed vesicles of a developmental stage equivalent to Day 10-14, Group 2 had two Day 23 fetuses, one collapsed vesicle (Day-17 size) and one vesicle without an embryo (Day-17 size). Group 3 had 4 fetuses at Day 23-24, and one resorbing and one vesicle without embryo at Day 17. Injection of $1 \mu \mathrm{g}$ oestradiol/10 days (Groups $4 \& 5$ ) caused reactivation of 1 blastocyst but in 6 animals no reactivation occurred. Nothing was recovered from 2 animals. One abnormal blastocyst was recovered from one animal treated with $10 \mu \mathrm{g}$ oestradiol/10 days (Group 6) and the uteri were empty in the 5 remaining animals. There was no reactivation in control animals (Group 7) in response to oil injection.

\section{Discussion}

Blastocyst reactivation in macropodid marsupials occurs after a wide range of experimental treatments with progesterone and oestrogen alone or in combination in pharmacological and physiological doses, during lactational and seasonal diapause, and in the presence or absence of an ovary or corpus luteum (Table 1). However, in all cases there is a high embryonic loss, showing that the doses and durations of treatment do not adequately mimic the normal events at reactivation.

In our study designed to test the relative roles of progesterone and oestrogen we were not able to improve the pregnancy rate by using confirmed physiological doses for the same or longer periods. Plasma progesterone concentrations measured in progesterone-treated animals were similar to late pregnancy values reported by Shaw \& Renfree (1984) although higher than those reported by Hinds \& Tyndale-Biscoe (1982). Plasma oestradiol concentrations in the low-dose oestradiol-treated animals were about the same as values before injection and also of pregnancy

(Shaw \& Renfree, 1984). In high-dose oestradiol-treated animals concentrations were higher than before injection or in normal pregnancy and about twice as high as in oestrous animals (Shaw \& Renfree, 1984; Harder et al., 1984).

Since oestradiol at a dose of $0.5 \mu \mathrm{g}$ can depress $\mathrm{LH}$ and $\mathrm{FSH}$ concentrations without significantly increasing levels of oestradiol measured in blood (Horn et al., 1985), it must be assumed that in the low-dose group there was sufficient circulating oestradiol to achieve an effect. This assumption was supported by the increased weight of the vaginal complex of the oestradioltreated animals. The vaginal weight increase induced by the high and low oestradiol treatments were similar to those found in normal oestrous females (Short et al., 1985) but the vaginal response was not dose-dependent. The above evidence suggests that $1 \mu \mathrm{g}$ oestradiol/day is a physiological dose for pregnancy, and that $10 \mu \mathrm{g}$ oestradiol/day duplicates or exceeds the higher peripheral plasma concentrations of oestrus. The weight increase in both endometrium and myometrium is much greater after progesterone for 18 days plus oestrogen for 3 days than that observed after treatment with progesterone for 10 days or combined with oestradiol for 10 days and is closer to weights of normal gravid uteri (Renfree \& Tyndale-Biscoe, 1973). The increase therefore appears to be largely due to the longer progesterone treatment than to any synergism between the two steroids.

About half the oestradiol-treated blastocysts remained quiescent, and the remaining half expanded slightly. Oestrogen treatment ( $2 \mu \mathrm{g}$ /day) can cause an immediate (within $24 \mathrm{~h}$ ) increase in uterine protein synthesis (Shaw \& Renfree, 1986), and we have shown also a slight increase in endometrial and myometrial weights. These uteri must therefore have an increased volume of secretion, and it is possible that the blastocyst expansion reflects an osmotic effect of altered uterine secretion on blastocyst integrity. The subsequent collapse of blastocysts could be due to insufficient secretion as the blastocyst begins to grow. In the absence of data on cell division, we must conclude that oestradiol alone is not capable of supporting embryonic growth after diapause. It may, however, contribute to the initiation of growth, as reported for the red kangaroo (Clark, 1968).

By contrast, progesterone alone or in combination with oestrogen can initiate and support embryonic growth to full term. There was no difference in proportion of animals with normal 
Table 1. Effects of exogenous steroids (progesterone $=P_{4}$; oestradiol-17 $\beta=E_{2}$ ) on diapausing blastocyst growth of macropodid marsupials $(\mathrm{T}=\operatorname{tammar} ; \mathrm{Q}=$ quokka; $\mathrm{R}=$ red kangaroo)

\begin{tabular}{|c|c|c|c|c|}
\hline Dose & Days & Fate of blastocysts & Species & Reference \\
\hline \multicolumn{5}{|c|}{ During seasonal diapause or after ovariectomy/excision of $\mathrm{CL}$} \\
\hline \multicolumn{5}{|c|}{ Progesterone } \\
\hline $10 \mathrm{mg}$ & $1-10$ & Half reactivate and develop to full term $\dagger$ & $\begin{array}{l}Q \\
T\end{array}$ & $\begin{array}{l}\text { Tyndale-Biscoe (1963) } \\
\text { Renfree \& Tyndale- } \\
\text { Biscoe (1973) }\end{array}$ \\
\hline $10 \mathrm{mg}$ & $1-18$ & Half reactivate and develop to full term $\dagger$ & $\mathbf{T}$ & This study \\
\hline \multirow[t]{2}{*}{$1-5 \mathrm{mg}$} & $1-5$ & Expand and collapse & Q & Tyndale-Biscoe (1963) \\
\hline & $i-3$ & Expand & $\mathrm{T}$ & Berger \& Sharman (1969) \\
\hline 2 and $5 \mathrm{mg}$ & $1-15$ & Expand and collapse & $\mathrm{T}$ & Renfree et al. (1982) \\
\hline \multicolumn{5}{|l|}{ Oestradiol } \\
\hline $100 \mu \mathrm{g}$ & $1-3$ & Expand and/or collapse & $\mathbf{T}$ & Smith \& Sharman (1969) \\
\hline $50 \mu \mathrm{g}$ & $1-3$ & Expand and/or collapse & $\mathbf{T}$ & Berger \& Sharman (1969) \\
\hline $10 \mu \mathrm{g}$ & 6 and 7 & Expand and/or collapse & Q & Tyndale-Biscoe (1963) \\
\hline $10 \mu \mathrm{g}$ & $1-10$ & Expand and/or collapse* & $\mathrm{T}$ & This study \\
\hline $1 \mu \mathrm{g}$ & $1-15$ & Expand, collapse or remain quiescent & $\mathbf{T}$ & Renfree et al. (1982) \\
\hline $1 \mu \mathrm{g}$ & $1-10$ & Expand, collapse or remain quiescent & $\mathbf{T}$ & This study \\
\hline \multicolumn{5}{|l|}{ Androstenedione } \\
\hline $5 \mathrm{mg}$ & $1-15$ & Remain quiescent & $\mathbf{T}$ & Renfree et al. (1982) \\
\hline \multicolumn{5}{|c|}{ Progesterone + oestradiol } \\
\hline $10 \mathrm{mg} \mathrm{P}_{4}$ & $\begin{array}{l}1-5 \\
6 \text { and } 7\end{array}$ & Half reactivate and develop to full term ${ }^{\dagger}$ & $Q$ & Tyndale-Biscoe (1963) \\
\hline $\begin{array}{l}10 \mathrm{mg} \mathrm{P}_{4} \\
+10 \mu \mathrm{g} \mathrm{E}_{2}\end{array}$ & & & & \\
\hline $\begin{array}{l}10 \mathrm{mg} \mathrm{P}_{4} \\
+1 \mu \mathrm{g} \mathrm{E}_{2}\end{array}$ & $1-10$ & Half reactivate and develop to full term $\dagger$ & $\mathrm{T}$ & This study \\
\hline $\begin{array}{l}10 \mathrm{mg} \mathrm{P}_{4} \\
\quad+1 \mu \mathrm{g} \mathrm{E}_{2}\end{array}$ & $1-3$ & Half reactivate and develop to full term $\dagger$ & $\mathbf{T}$ & This study \\
\hline $10 \mathrm{mg} \mathrm{P}_{4}$ & $4-18$ & & & \\
\hline $\begin{array}{l}2 \mathrm{mg} \mathrm{P}_{4} \\
\quad+1 \mu \mathrm{g} \mathrm{E}{ }_{2}\end{array}$ & $1-15$ & Expand and/or collapse* & $\mathrm{T}$ & Renfree et al. (1982) \\
\hline \multicolumn{5}{|l|}{ During lactation +} \\
\hline $\begin{array}{l}5,10 \text { or } \\
20 \mathrm{mg} \mathrm{P}_{4}\end{array}$ & $1-3$ & Birth occurred $3-4$ days early & $\mathbf{R}$ & Clark (1968) \\
\hline $\begin{array}{l}20-200 \\
\mu \mathrm{gE}_{2}\end{array}$ & $1-3$ & Birth occurred 3-4 days early in half & $\mathbf{R}$ & Clark (1968) \\
\hline
\end{tabular}

*Nothing found in the uterus of a high proportion of these animals at autopsy.

$\lceil$ Full term occurs 3-4 days earlier than after RPY (Renfree \& Tyndale-Biscoe, 1973).

$\ddagger$ RPY at Day 4.

embryonic development between those treated with progesterone and oestrogen and those treated with progesterone alone. Our failure to improve on the $50 \%$ success rate with longer treatment combined with oestrogen leads us to conclude that there is no synergistic effect of exogenous progesterone and oestradiol on blastocyst reactivation, and there must be other factors responsible for normal embryonic development. The corpus luteum is essential for only the first 8 days after removal of pouch young (Tyndale-Biscoe, 1963, 1970) and the failure of most embryos occurs within this period, so it is possible that the normal reactivated corpus luteum produces something as yet unidentified. Alternatively, the more sustained high levels of steroid achieved with injections in oil may not sufficiently reflect the wide oscillations in both oestradiol and progesterone concentrations observed in early tammar pregnancy (Fletcher \& Renfree, 1988). It remains possible that low endogenous levels of oestradiol may be adequate for synergism and support the dominant role of progesterone for initiation of active pregnancy after diapause.

We thank D. Blanden, Dr K. Gordon and Dr G. Shaw for assistance in collecting blood samples and at autopsy, and Dr G. Shaw for constructive comments on the manuscript. This study 
was supported by Australian Research Grants Scheme Program Grant A1851504P and permit No. 84-28 from Department of Conservation, Forests and Lands, Victoria, Australia.

\section{References}

Berger, P.J. \& Sharman, G.B. (1969) Progesteroneinduced development of dormant blastocysts in the tammar wallaby, Macropus eugenii Desmarest: Marsupialia. J. Reprod. Fert. 20, 201-210.

Clark, M.J. (1968) Termination of embryonic diapause in the red kangaroo, Megaleia rufa, by injection of progesterone or oestrogen. J. Reprod. Fert. 15, 347-355.

Fletcher, T.P. \& Renfree, M.B. (1988) Effects of corpus luteum removal on progesterone, oestradiol-17 $\beta$ and LH in early pregnancy of the tammar wallaby, Macropus eugenii. J. Reprod. Fert. 83, 185-191.

Harder, J.D., Hinds, L.A., Horn, C.A. \& Tyndale-Biscoe, C.H. (1984) Oestradiol in follicular fluid and in utero-ovarian venous and peripheral plasma during parturition and post-partum oestrus in the tammar, Macropus eugenii. J. Reprod. Fert. 72, 551-558.

Hinds, L.A. \& Tyndale-Biscoe, C.H. (1982) Plasma progesterone levels in the pregnant and non-pregnant tammar, Macropus eugenii. J. Endocr. 93, 99-107.

Horn, C.A., Fletcher, T.P. \& Carpenter, S. (1985) Effects of oestradiol-17 $\beta$ on peripheral plasma concentrations of LH and FSH in ovariectomized tammars (Macropus eugenii). J. Reprod. Fert. 73, 585-592.

Nie, N., Bent, D.H. \& Hull, C.H. (1986) SPSS-X Users' Guide, 2nd edn. McGraw-Hill, New York.

Renfree, M.B. \& Tyndale-Biscoe, C.H. (1973) Intrauterine development after diapause in the marsupial, Macropus eugenii. Devl Biol. 32, 2840.

Renfree, M.B., Wallace, G.I. \& Young, I.R. (1982) Effects of progesterone, oestradiol-17 $\beta$ and androstenedione on follicular growth after removal of the corpus luteum during lactational and seasonal quiescence in the tammar wallaby. J. Endocr. 92, $397-403$.

Ryan, B.F., Joiner, B.L. \& Ryan, T.A. (1985) Minitab Handbook, 2nd edn. Duxbury Press, Boston.

Shaw, G. \& Renfree, M.B. (1984) Concentrations of oestradiol-17 $\beta$ in plasma and corpora lutea throughout pregnancy in the tammar, Macropus eugenii. $J$. Reprod. Fert. 72, 29-37.

Shaw, G. \& Renfree, M.B. (1986) Uterine and embryonic metabolism after diapause in the tammar wallaby, Macropus eugenii. J. Reprod. Fert. 76, 339-347.

Short, R.V., Flint, A.P.F. \& Renfree, M.B. (1985) Influence of passive immunization against $\mathrm{GnRH}$ on pregnancy and parturition in the tammar wallaby, Macropus eugenii. J. Reprod. Fert. 75, 567-575.

Smith, M.J. \& Sharman, G.B. (1969) Development of dormant blastocysts induced by oestrogen in the ovariectomised marsupial, Macropus eugenii. Aust.J. biol. Sci. 22, 171-180.

Tyndale-Biscoe, C.H. (1963) Effects of ovariectomy in the marsupial, Setonix brachyurus. J. Reprod. Fert. 6, 2540.

Tyndale-Biscoe, C.H. (1970) Resumption of development by quiescent blastocysts transferred to primed, ovariectomized recipients in the marsupial, Macropus eugenii. J. Reprod. Fert. 23, 25-32.

Tyndale-Biscoe, C.H. \& Renfree, M.B. (1987) Reproductive Physiology of Marsupials, Cambridge University Press.

Received 4 August 1987 